\title{
THE ATRIAL ELECTROGRAM IN MITRAL STENOSIS
}

\author{
BY \\ GEOFFREY REYNOLDS
}

From The Cardiac Department and Thoracic Surgical Unit, Guy's Hospital

Received November 20, 1952

The exposure of the heart during the operation of mitral valvotomy has presented the opportunity of obtaining electrograms from the outer surface of the atria of cases of mitral stenosis. Analysis of these tracings has helped to explain the cause of the broad, notched $P$ wave often seen in this condition. Since only a single-channel electrocardiograph was available, the correlation of the various deflections in the two atrial leads with each other and with those from indirect leads was not as accurate as could be wished, but it has been sufficient for certain conclusions to be drawn.

Unipolar leads were used-a pad of cotton wool soaked in saline and attached to a loop of silver wire forming the exploring electrode. Leads were taken from the body of the right atrium and from the body and appendage of the left atrium in positions as similar as possible in each case; though it was not possible to place the electrode so accurately on the right atrium, since its exposure was not so good as that of the left. Records were usually made at the full standardization of a one-centimetre deflection representing one millivolt, but this had sometimes to be reduced a variable amount.

One important technical problem was to prevent distortion of the record by the mechanical effect of the contraction of the heart: this, however, was mainly ventricular and so, coming after the QRS complex, did not distort the earlier, more important deflections.' More troublesome were the ectopic arrhythmias that are frequently seen during this operation (Campbell and Reynolds, 1952) and occasionally no record of the sinus rhythm was obtained.

Measurements were made of the height and width of the $P$ waves, and of the $P-R$ interval from the beginning and peak of the major deflection of the $P$ wave to the beginning and peak of the major deflection of the QRS complex. Where positive and negative deflections were approximately equal an average of the two was taken.

These investigations have been carried out in 29 cases of mitral stenosis, but the findings were incomplete in 4 of these due to a distorted record in one and an ectopic pacemaker in three. Similar investigations were made for comparison in 11 cases of congenital heart disease and in 8 of carcinoma of the bronchus.

\section{RESULTS}

There was a wide variation in the size and shape of the $P$ waves in the atrial tracings, though this was not as great as the extremes of the ranges might suggest. Table I shows the average of these measurements in the three groups of cases studied; and the relationship in size and time between the two atrial $\mathbf{P}$ waves in the three groups is shown diagrammatically in Fig. 1. Representative standard leads and atrial electrograms from eight of the cases of mitral stenosis are illustrated later in Fig. 2 and 3.

The form of the $P$ wave from the right atrium of the cases with mitral stenosis varied from an entirely positive to an entirely negative deflection, and predominantly positive and predominantly negative deflections were present in about equal numbers. From the left atrium a positive 
TABLE I

Average Measurements of the P Waves in the Atrial Electrograms in the Control Cases, in Mitral Stenosis, and in Congenital Heart Disease

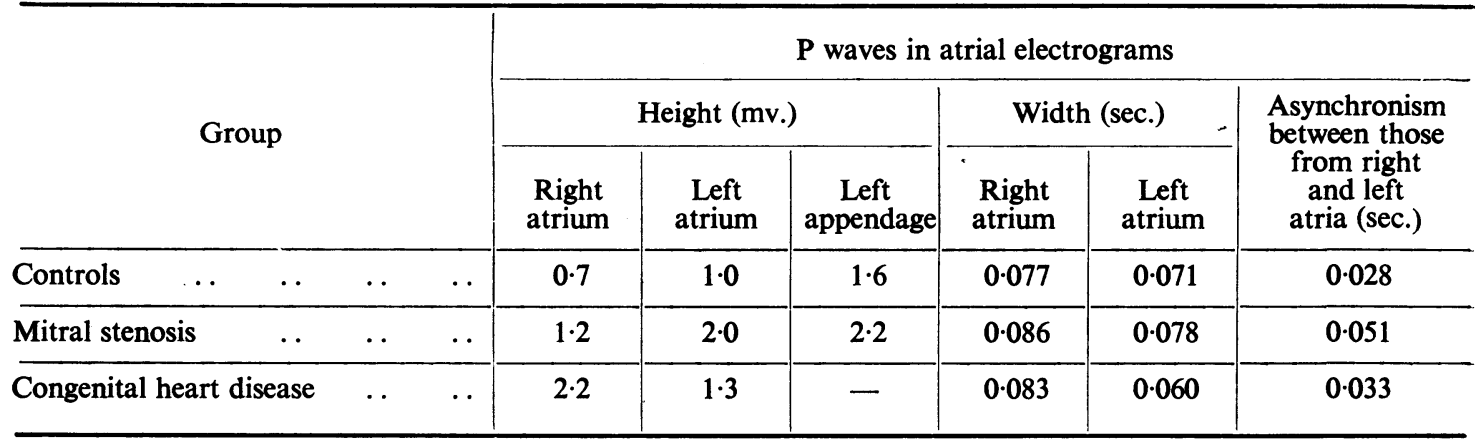

deflection was usually equal to or greater than the negative one, and from the left appendage was always so.

The height of the $P$ wave from the right atrium varied between 0.5 and $3.2 \mathrm{mv}$, with an average of $1.2 \mathrm{mv}$.; that from the left atrium between 0.4 and $4.8 \mathrm{mv}$., with an average of $2.0 \mathrm{mv}$.; and that from the left appendage between 0.4 and $3.6 \mathrm{mv}$., with an average of $2.2 \mathrm{mv}$. The average voltage of the $\mathbf{P}$ wave from the right atrium was one and a half times as large as in the control cases with carcinoma of the bronchus $(0.7 \mathrm{mv}$.), but only half as large as in those with congenital heart disease $(2 \cdot 2 \mathrm{mv}$.). The average voltage of the $\mathrm{P}$ wave from the left atrium was twice that in the controls $(1.0 \mathrm{mv}$.) and one and a half times that in the congenital heart cases $(1.3 \mathrm{mv}$.) (Table I). There was no relation between the voltages of the $P$ waves from the two chambers in individual cases.

The width of the $P$ wave recorded from either atrium was usually only about two-thirds of that in the standard leads, because the deflection in either atrium appeared to be derived solely from that atrium. Occasionally the $\mathbf{P}$ wave in the direct tracing was as wide as that in the standard leads, and then this was usually due to a low wave before or after the main deflection that, judged by its timing, represented activity in the other atrium and could be recognized as such without difficulty (Fig. 3). In mitral stenosis the average width of the $P$ wave was $0.086 \mathrm{sec}$. in the right atrial tracing, and $0.078 \mathrm{sec}$. in the left. These were slightly greater than the figures in the controls, which were respectively 0.077 and $0.071 \mathrm{sec}$. In the cases with congenital heart disease the $P$ wave from the right atrium was $0.083 \mathrm{sec}$, , but that from the left was only $0.06 \mathrm{sec}$. (Table I.)
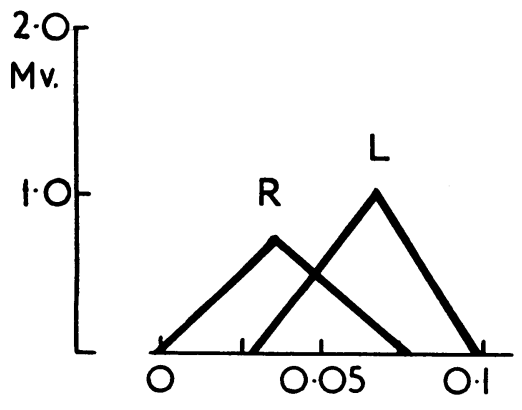

CONTROL

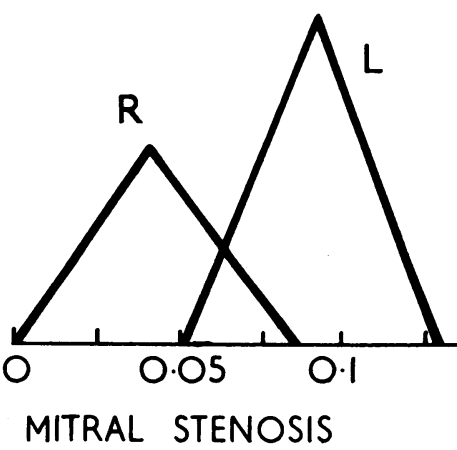

MITRAL STENOSIS

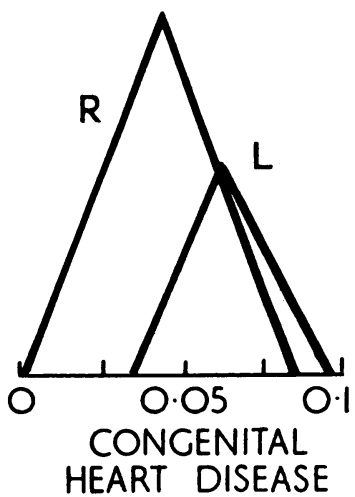

HEART DISEASE

Fig. 1.-Diagrammatic representation of the relationship in size and time between the $\mathbf{P}$ waves in the right and left atrial electrograms of the control cases with carcinoma of the bronchus, cases with mitral stenosis, and those with congenital heart disease. 


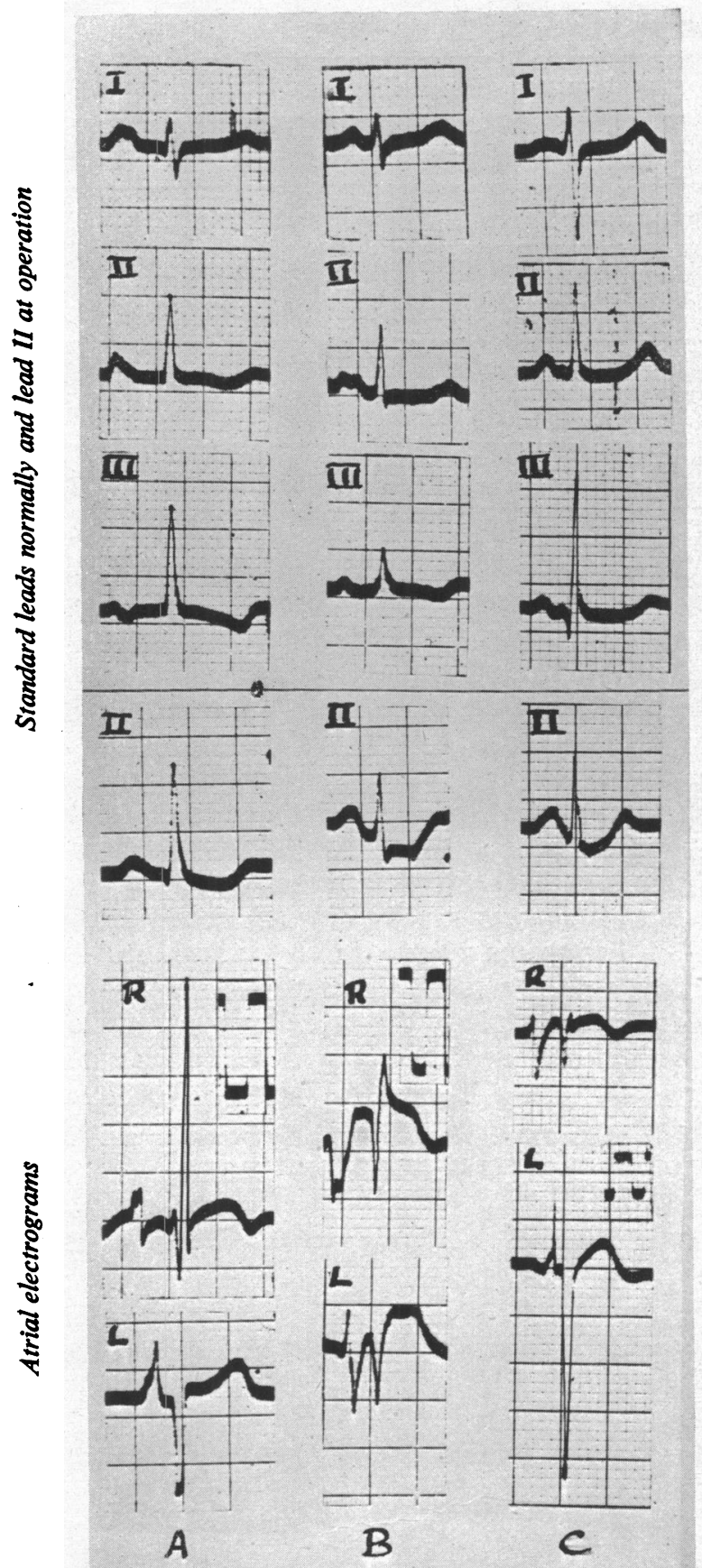

FIG. 2.-The three standard leads normally, standard lead II during operation, and the right and left atrial electrograms of three cases of mitral stenosis, showing by their different behaviour the individuality of the two components of the $\mathbf{P}$ waves in the standard leads and their correspondence in time with the $P$ waves in the two atrial tracings. (Standardization, as indicated, is the same for both atrial electrograms of each case.)
The most striking difference between the tracings from the two atria in the cases of mitral stenosis was seen in their P-R intervals, and this was sometimes obvious at a casual glance. The intervals were always longer from the right than from the left atrium -in one case as much as double. The difference varied from 0.02 to $0.10 \mathrm{sec}$. and became greater as the $P$ wave in the standard leads became wider and more notched. Moreover, whether the P-R intervals were measured from the beginning or peak of the $P$ wave (ignoring in the left atrial tracings the small preceding wave from the right atrium when this was present) to the beginning or peak of the QRS complex, their difference was approximately the same as the difference between the two peaks or the standard $\mathrm{P}$ wave or between the edges of its plateau. Fig. 4 shows the good correlation between the difference of the P-R intervals (measured in (A) from the beginning and in (B) from the peak of the $P$ waves to the beginning of the QRS complexes) and the distance separating the peaks of the standard $\mathbf{P}$ wave in that case. This indicates that the first peak corresponds to the right atrial $P$ wave and the second to the left.

The average difference between the $\mathbf{P}-\mathbf{R}$ intervals from the two atria in the cases of mitral stenosis, as measured from the beginning of the $\mathbf{P}$ wave to the beginning of the QRS complex, was 0.051 sec., and the average distance between the peaks of the standard $P$ waves was also $0.051 \mathrm{sec}$. A similar correlation was present in the control group; here, however, the average difference between the P-R intervals was only $0.028 \mathrm{sec}$. and the distance between the peaks of the standard $P$ waves was $0.031 \mathrm{sec}$. In the group with congenital heart lesions the average difference between the $P-R$ intervals was $0.033 \mathrm{sec}$., but the peak to peak measurement of the standard $P$ waves was only $0.018 \mathrm{sec}$. This was undoubtedly due to four of the eleven cases having no distinguishable second peak although the direct tracings showed asynchronous $P$ waves: the discrepancy is caused by the peak of the left atrial $\mathbf{P}$ wave being hidden in the large $\mathbf{P}$ from the hypertrophied right atrium, which produces the tall, pointed $P$ wave so characteristic of many of these conditions (Table I). 
Tracings from the left atrial appendage were taken in 18 of the cases of mitral stenosis. The $\mathbf{P}$ wave was often very similar to that from the body of the left atrium, but usually more positive and its peak slightly later. Occasionally the peak of the predominant, positive deflection in the

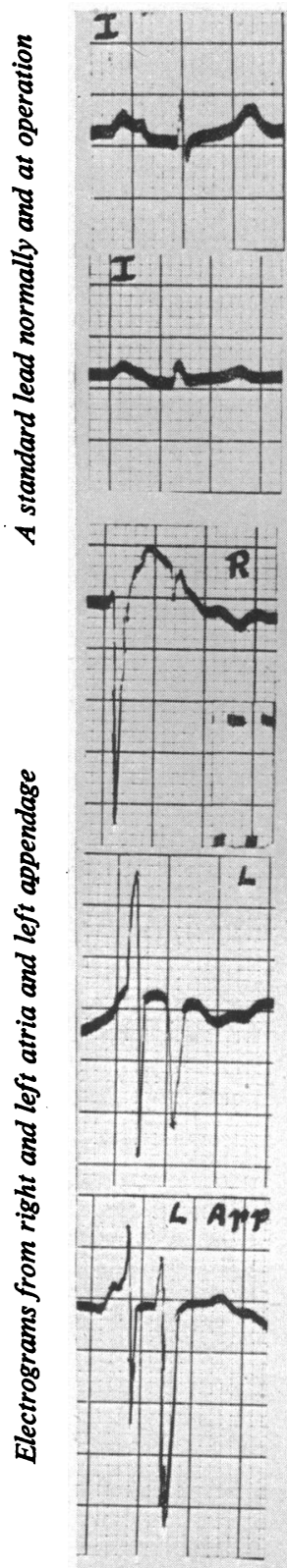

A
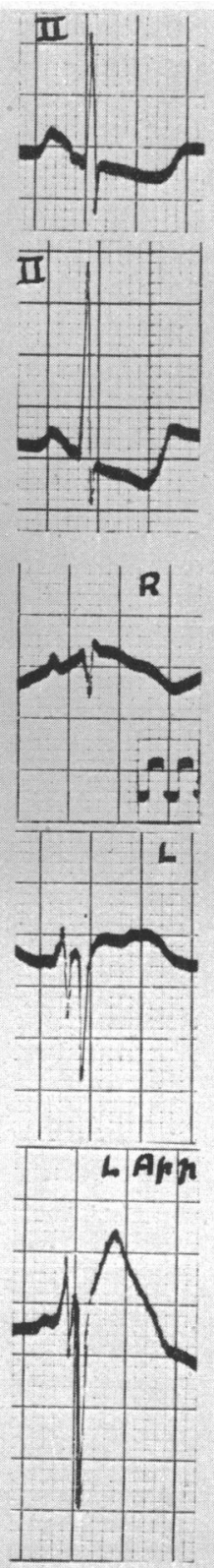

B
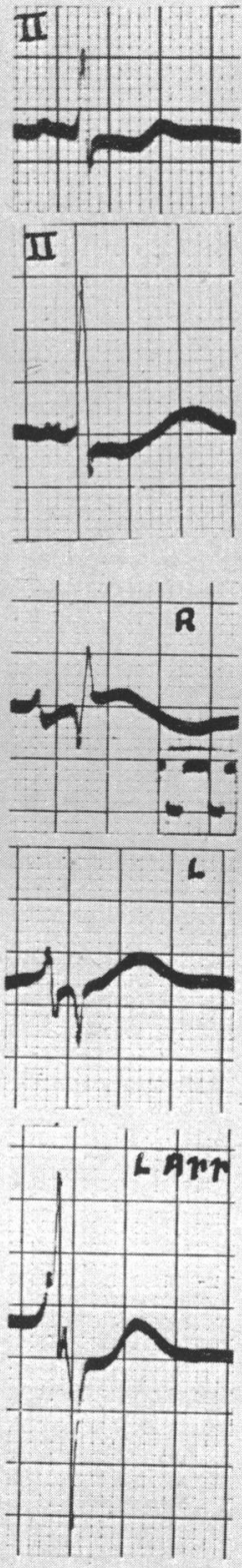

C
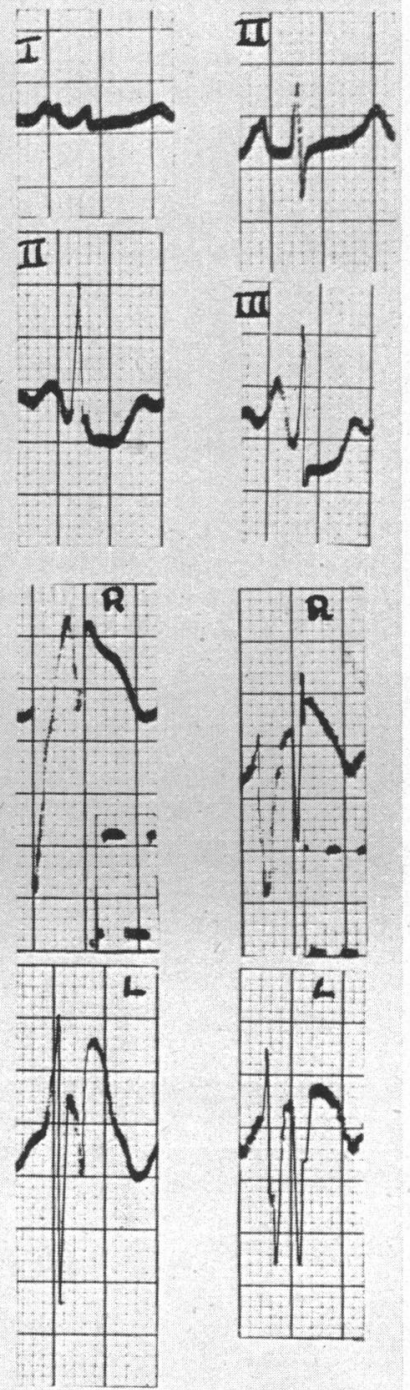

D

$E$

FIG. 3.-A standard lead normally and during operation, the right and left atrial electrograms in five cases of mitral stenosis, and the electrogram from the left atrial appendage in three of these, showing the relation between the two components of the standard $\mathbf{P}$ wave and the $\mathbf{P}$ waves in the right and left atrial electrograms. A small wave representing activity in the right atrium can be seen in the left atrial electrogram in (A) and (B). (Standardization, as indicated, is the same for all atrial electrograms of each case). 


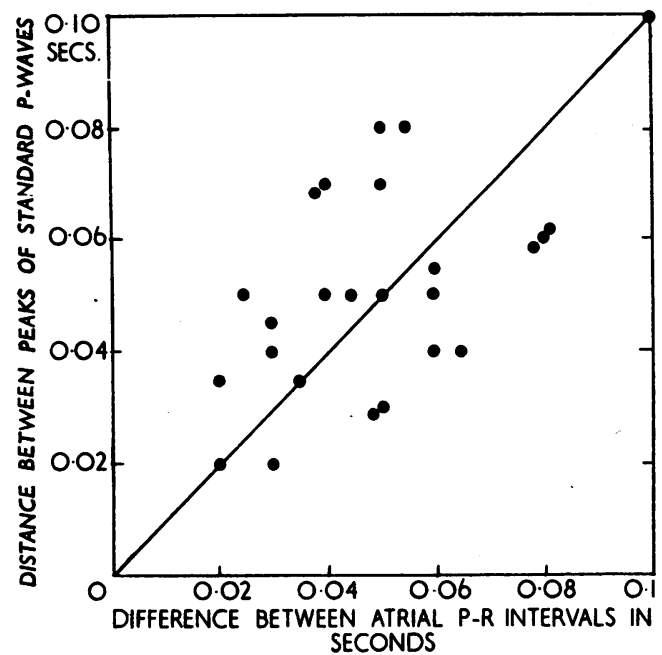

A

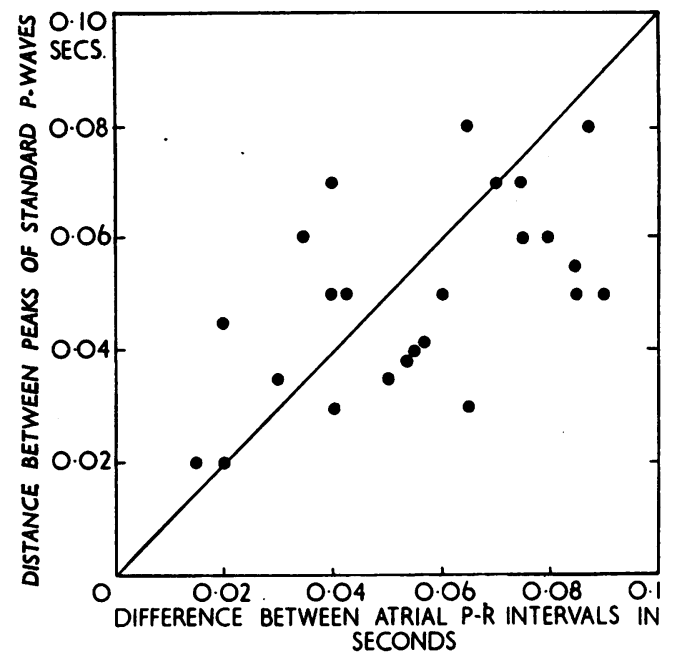

B

FIG. 4.- Showing the relation between the distance separating the two peaks of the $P$ wave in the standard leads and the difference between the P-R intervals in the right and left atrial electrograms measured, in (A) from the onset of QRS and, in (B) from the peak of $P$ to the onset of QRS, in 25 cases of mitral stenosis.

lead from the appendage corresponded to the peak of a smaller, negative deflection in the lead from the body of the left atrium (Fig. 3C).

A comparison between the difference of the $P-R$ intervals from the two atrial tracings and the voltage of their $P$ waves showed the average height of the left atrial $P$ waves to be $1.6 \mathrm{mv}$. in the ten cases with the most asynchronism of the atria, and $2.5 \mathrm{mv}$. in the ten cases with the least asynchronism-a difference that is more than twice its standard error. The average height of the $P$ waves from the right atria was similar in both these groups (Table II).

TABLE II

The Size of the P Waves, and the Cardiothoracic Ratios in Patients with Different Degrees of ASYNCHRONISM OF THE RIGHT AND LefT ATRIAL P WAVES

\begin{tabular}{|c|c|c|c|c|c|c|c|}
\hline \multirow[t]{2}{*}{. } & & \multirow{2}{*}{$\begin{array}{c}\text { Number } \\
\text { of } \\
\text { cases }\end{array}$} & \multicolumn{2}{|c|}{$\begin{array}{l}\mathbf{P} \text { wave in } \\
\text { standard leads }\end{array}$} & \multicolumn{2}{|c|}{$\begin{array}{c}\text { Height of } \mathbf{P} \text { wave } \\
\text { in atrial } \\
\text { electrogram }\end{array}$} & \multirow{2}{*}{$\begin{array}{l}\text { Cardio- } \\
\text { thoracic } \\
\text { ratio }\end{array}$} \\
\hline & & & $\begin{array}{l}\text { Width } \\
\text { (sec.) }\end{array}$ & $\begin{array}{l}\text { Height } \\
\text { (mv.) }\end{array}$ & $\begin{array}{l}\text { Right } \\
\text { atrium } \\
\text { (mv.) }\end{array}$ & $\begin{array}{l}\underset{\text { Left }}{\text { Latrium }} \\
\text { (mv.) }\end{array}$ & \\
\hline \multirow{3}{*}{$\begin{array}{l}\text { Degree of asynchronism in } 25 \text { cases of mitral } \\
\text { stenosis (sec.) }\end{array}$} & $\begin{array}{l}\text { More } \\
\text { than } \\
0.05\end{array}$ & 10 & 0.135 & 0.14 & $1 \cdot 3$ & $1 \cdot 6$ & $56 \cdot 4$ \\
\hline & 0.05 & 5 & $0 \cdot 116$ & $0 \cdot 18$ & 0.9 & $1 \cdot 8$ & $58 \cdot 6$ \\
\hline & $\begin{array}{l}\text { Less } \\
\text { than } \\
0.05\end{array}$ & 10 & $0 \cdot 108$ & 0.185 & $1 \cdot 3$ & $2 \cdot 5$ & 51.5 \\
\hline
\end{tabular}

Comparison between the $\mathbf{P}$ waves in the standard leads and those in the direct atrial tracings showed that the former were taller where the voltage of the P waves was high in either of the atrial leads, though the difference was small (Table III). There was no relation between the widths of 
the standard and atrial $\mathbf{P}$ waves, but the standard $\mathbf{P}$ waves were widest in those cases where asynchronism of the atria was greatest (Table II).

TABLE III

Relationship of Height of P Waves in Atrial Electrograms to that in the Standard Leads and to the Cardiothoracic Ratio, in 25 Cases of Mitral Stenosis

\begin{tabular}{l|c|c|c}
\hline & $\begin{array}{c}\text { Height of P waves } \\
\text { in standard leads (mv.) }\end{array}$ & $\begin{array}{c}\text { Cardio-thoracic } \\
\text { ratio }\end{array}$ \\
\hline & $\begin{array}{c}\text { Both } \\
\text { atria }\end{array}$ & 0.175 & 52.7 \\
\cline { 2 - 3 } & $\begin{array}{c}\text { Left } \\
\text { atrium }\end{array}$ & 0.171 & 54.3 \\
\hline $\begin{array}{c}\text { Right } \\
\text { leads from }\end{array}$ & 0.175 & 55.0 \\
\hline $\begin{array}{c}\text { atrium } \\
\text { Neither } \\
\text { atrium }\end{array}$ & 0.142 & 56.2 \\
\hline
\end{tabular}

Comparison of the voltage of the atrial $\mathrm{P}$ waves and the degree of their asynchronism with the pressures in the atria and pulmonary artery, whether taken at operation or during a previous catheterization, showed no correlation. In particular there was no correlation between the pressure and size of the $\mathrm{P}$ wave from the corresponding atrium.

Comparison of the voltage of the atrial $\mathbf{P}$ waves and the degree of their asynchronism with the clinical state of the patient showed no correlation with the length or degree of disability; there was a good correlation, however, with the cardiothoracic ratio (c.t.r.). The average c.t.r. was 56.4 in the ten cases with asynchronism of the atrial $P$ waves above $0.05 \mathrm{sec}$., while it was only 51.5 in the ten cases with an asynchronism below $0.05 \mathrm{sec}$ (Table II); and this difference is three times its standard error. On the other hand the c.t.r. was high in those cases where the voltage was low, and low in those where a high voltage was present in one, and particularly in both atrial tracings (Table III).

\section{Discussion}

Several criticisms may be levelled against the significance given to these findings. The leads compared were not simultaneous tracings and so the time relation between them could not always be decided with complete certainty. Notching of the $\mathbf{P}$ waves in the standard leads was not always visible at the time the atrial tracings were taken, and the latter had, therefore, to be compared with a standard lead taken some time earlier. Multiple tracings from one atrium showed that the peak of the major deflection of the $P$ wave was not reached at exactly the same time at all points on the atrium. But any errors introduced through these factors are thought to be more likely to diminish than to increase the evidence on which the significance of the findings is based.

There was sufficient correlation between the height of the $\mathbf{P}$ waves in the standard leads and those in the two atrial tracings to suggest that increase in the voltage of the $P$ wave in either the right or left atrial electrogram will cause a larger $\mathbf{P}$ wave in the standard leads. But no exact correlation can be expected since the size of the $P$ wave in the standard leads must also be influenced by the axis of the wave in relation to the frontal plane, and by the degree of overlapping, and therefore of summation, of its component parts-the atrial $P$ waves.

The absence of any correlation between the width of the $P$ waves in the standard leads and of those in the direct leads is not surprising for, as can be seen from Fig. 1, the width shown in the standard leads will depend more on the degree of asynchronism in the direct leads, and with this there is a good agreement. 
The absence of any correlation between the voltage of the $P$ waves in the direct leads and the atrial and pulmonary artery pressures may be compared with the lack of correlation between the size of the $P$ waves in the standard leads and these pressures which was found by Trounce (1952) in similar cases of mitral stenosis.

Several points of interest have been demonstrated. First that the normal asynchronous appearance of the $\mathbf{P}$ waves in the right and left atrial electrograms-and, therefore, of the contraction of the atria, since "the order of excitation and contraction are identical" (Lewis, 1925)-is often increased in mitral stenosis and thus gives rise to the characteristic broad, notched $P$ wave of this condition; and, moreover, that the two peaks of the notched wave correspond to the deflections from the right and left atria, the widening and notching revealing the double origin of the wave in the standard leads.

This double origin of the standard $\mathbf{P}$ wave can often be discerned, even in the normal cardiogram. Lewis and Gilder (1912) found that more than 30 per cent of normal P waves in lead II were notched, while Trendelenberg (1933) goes so far as to say that P II has always at least two peaks. Fredericq demonstrated as long ago as 1906 that in dogs the contractions of the atria were not synchronous, though Lewis (1925), while showing that the impulse reached the right atrium $0.021 \mathrm{sec}$., and finally the left appendage $0.045 \mathrm{sec}$, after its origin in the S-A node, stated that it was not true that the whole of the right atrium contracts before the left. Prinzmetal (1950), indeed, demonstrated synchronous contraction of the atrial appendages in dogs, and says that human atria behave similarly. But Levine et al. (1949) using intracardiac and osophageal leads in man found that, although there may be some overlapping, the left atrium is stimulated 0.05 to $0.07 \mathrm{sec}$. later than the right; while Groedel and Borchardt (1948) using leads on the heart outside the pericardium also confirmed this asynchronism, though they put it at 0.03 to $0.04 \mathrm{sec}$. with which our figures are in better agreement. But it is doubtful whether it is generally recognized, as Lambert (1939) states that it is, that this asynchronism of the atrial contractions exists or that it is the cause of the notching of the standard $P$ wave.

The dual origin of the standard $P$ wave is well demonstrated by the different behaviour of the two components of the $\mathrm{P}$ waves in the standard leads (Fig. 2). In Fig. 2A the initial, right atrial half has a normal axis since it is positive in all three leads, while the later, left atrial component has a left axis deviation, being positive in lead I but negative in lead III. In Fig. 2B both components are positive in lead II, while that from the right atrium is flat in lead I and that from the left is flat in lead III. Fig. 2C shows almost complete separation of the two components of the $P$ waves in leads II and III due to the striking difference in the P-R intervals that is seen in the atrial electrograms.

The excessive width of the " $P$ mitrale" is generally recognized as being due to the increased time taken by the impulse to pass across the atria, though it remains undecided whether this is due to an enlarged left atrium (Wood, 1950), to local retardations in this atrium (Wenger and Hofmann-Credner, 1952), or to delayed inter-atrial conduction (Berconsky and Kloztman, 1945). If the $P$ wave we have recorded directly from the left atrium represents the spread of the impulse through the wall of the whole of this chamber, the delay in its onset in cases where the $P$ wave in the standard leads is widened suggests that the widening is due to a delay in the impulse reaching the left atrium. This might be due to dilatation of the right atrium, but there was no correlation between the asynchronism of the $\mathbf{P}$ waves in the two atrial tracings and the width of that from the right atrium; or it might be due to delay in conduction between the two atria. Fredericq (1906) found no evidence of specific conducting tissue between the atria in dogs; but Lewis et al. (1914) demonstrated in these animals a high rate of conduction between the region of the sino-atrial node and the left atrial appendage due to a straight band of fibres running between them; and Bachmann (1916) was able to increase the asynchronism of the atrial contractions three or four fold by crushing this interatrial band. No exactly similar structure is described in man; though here, too, the atrial musculature common to both chambers occurs in two localized groups (Walmsley, 1929), and " fairly direct fibres passing to the left auricle and to the auriculo-ventricular node excite these regions somewhat 
in advance of the more distal regions of the right auricle itself simply because of the length of the pathway" (Fulton, 1949).

Alternatively, the $P$ wave in the left atrial tracing may represent the impulse in only a limited area of the atrial wall, which becomes a relatively smaller part of the chamber as this increases in size; the delay in the onset of the $P$ wave would then be due to the delay in the impulse reaching that part of the atrium from which the lead is taken, having first had to traverse other areas of the enlarged left atrium. The sharply defined onset of the $P$ wave in most of the direct tracings, however, suggests that it represents the impulse throughout the atrium and that the increase in the asynchronism of the $P$ waves in the right and left atrial electrograms is due to delay in the impulse reaching the left atrium. It is tempting to postulate that this is due to a naturally occurring lesion in some such inter-atrial band as that in which Bachmann (1916) produced similar changes experimentally in dogs.

Other points of interest are that the patients with the greatest asynchronism of the atria tended to have the lowest voltage of the $P$ waves in the left atrial tracings and to have large hearts, while the patients with normal asynchronism of the atria were those who tended to have a high voltage of the $P$ waves in the left atrial tracings and to have small hearts. These findings are only applicable to cases such as those investigated here, that is cases of mitral stenosis where the patient is sufficiently disabled to have operative treatment. In these the findings are not irrational. Left atrial hypertrophy might be expected in all cases of mitral stenosis. High voltage of the $P$ wave in the left atrial tracings is evidence of this, but the converse-that normal or low-voltage $P$ waves indicate no hypertrophy-is probably not true. It is more probable that the high-voltage $P$ waves indicate a well functioning and the lower voltage a poorly functioning atrial myocardium (Berliner and Master, 1938), the latter perhaps due to the length of time or the severity of the increased work imposed on the muscle, or due to the effect of the past rheumatic infection. In many cases the conditions of the atrial and ventricular myocardium are likely to be similar. It is not surprising, therefore, to find little enlargement of the heart when the atrial electrogram, by a large $P$ wave, shows evidence of a good atrial myocardium, and a large heart when there is evidence from a small $P$ wave in the electrogram of a poor myocardium. Increased asynchronism is likely to occur from the same cause - a poor atrial myocardium - either directly due to a general or local slowing of conduction, or indirectly due to a lowered resistance to dilatation.

It is possible that the form of the $P$ wave in the standard leads may be able to provide earlier information about the state of the myocardium than the cardio-thoracic ratio.

\section{SUMMARY}

Electrograms have been taken from the outer surfaces of the right and left atria in 29 cases of mitral stenosis, 11 cases of congenital heart disease, and 8 control cases of carcinoma of the bronchus.

Compared with the control cases, the voltages of the $\mathbf{P}$ waves were increased in mitral stenosis especially in the left atrial tracings, and in congenital heart disease mainly in the right atrial tracings.

Asynchronism of the $\mathbf{P}$ waves in the right and left atrial tracings was present in every case. The average difference was $0.05 \mathrm{sec}$. in mitral stenosis, compared with $0.03 \mathrm{sec}$. in the controls and in congenital heart disease. This increased asynchronism accounts for the widening and notching of the $\mathbf{P}$ waves often seen in the standard leads of patients with mitral stenosis. The first peak is derived from the right atrium, the second from the left.

The voltage of the $P$ wave in the left atrial electrogram was, on the average, significantly higher in patients with little or no cardiac enlargement; asynchronism of the $P$ waves in the two atrial tracings was greater in those whose hearts were large. It appears that this asynchronism is likely to increase when the failure of the voltage of the left atrial $P$ wave to increase suggests a poor atrial myocardium; and in these cases a high cardiothoracic ratio will often be present to suggest a poor ventricular myocardium also.

I wish to thank Mr. R. C. Brock and Mr. B. B. Milstein for their help in obtaining these records from hearts on which they were operating, Dr. Charles Baker for providing the clinical data and Dr. Albert Venner for the intracardiac pressures of these patients, and Dr. Maurice Campbell for his help in preparing this paper. 


\section{REFERENCES}

Bachmann, G. (1916). Amer. J. Physiol., 41, 309.

Berliner, K., and Master, A. M. (1938). Arch. intern. Med., $61,39$.

Berconsky, I., and Kloztman, M. (1945). Medicina, 5, 347; quoted by Wood, P. (1950).

Campbell, M., and Reynolds, G. (1952). Cardiologia, 21, 642.

Fredericq, L. (1906). Arch. internat. Physiol., 4, 57.

Fulton, J.F. (1949). Textbook of Physiology. 16th ed., W. B. Saunders and Co., Philadelphia.

Groedel, F. M., and Borchardt, P. R. (1948). Direct Electrocardiography of the Human Heart. Brooklyn Medical Press, New York.

Lambert, J. (1939). Bull. Soc. belge Cardiol., 6th year, No. 3.

Levine, H. D., Hellems, H. K., Wittenborg, M. H., and Dexter, L. (1949). Amer. Heart J., 37, 46.

Lewis, T. (1925). The Mechanism and Graphic Registration of the Heart Beat. 2nd ed., Shaw and Sons, London. , and Gilder, M. D. D. (1912). Phil. Trans., 202, 351.

-, Meakins, J., and White, P.D. (1914). Phil. Trans., 205, 375.

Prinzmetal, M., Corday, E., Brill, I. C., Oblath, R. W., and Kruger, H. E. (1952). The Auricular Arrhythmias. Charles C. Thomas, Springfield, Illinois.

Trendelenberg, W. (1933). Z. ges. exp. Med., 92, 20.

Trounce, J. R. (1952). Brit. Heart J., 14, 185.

Walmsley, T. (1929). Quain's Anatomy. Vol. 4, Part 3, Longmans, Green and Co., London.

Wenger, R., and Hofmann-Credner, D. (1952). Circulation, 5, 870.

Wood, P. (1950). Diseases of the Heart and Circulation. Eyre and Spottiswoode, London. 